\title{
Is There a Demand for Flood Insurance in Vietnam? Results From a Choice Experiment
}

\author{
Arnaud Reynaud • Manh-Hung Nguyen • \\ Cécile Aubert
}

\begin{abstract}
Vietnam is one of the countries most affected by floods. Despite high exposure to this risk and repeated calls from international organizations, the penetration rate of flood insurance remains surprisingly low in Vietnam. We investigate if there is a demand for flood insurance by Vietnamese households using a choice experiment. We compute households' willingness to pay (WTP) for various flood insurance programs and we identify the relationships between WTP and the different attributes of insurance schemes (type of risk covered, level of coverage, insurance provider, billing frequency, insurance premium). We first show that Vietnamese households exhibit a strong preference for the status quo option (no insurance). We do, however, document significant and positive WTP for some flood insurance policies, especially those covering health expenses. We show that household trust in institutions providing flood insurance policies may help understand the currently low adoption rate. Finally, we stress the high degree of heterogeneity in household preferences for flood insurance policies: past experience with flooding, individual risk preferences and subjective flood risk perception matter to understand WTP for flood insurance. These results call for a very careful design of flood insurance mechanisms in Vietnam, and more generally in developing countries subject to high risks of natural disasters.
\end{abstract}

Keywords Flood · Insurance · Vietnam · Valuation · Choice Experiment

JEL Codes: Q51, Q53, Q25

\footnotetext{
A. Reynaud

Toulouse School of Economics, INRA, University of Toulouse Capitole, Toulouse, Tel.: +33561128512, Fax:+33-561128520, E-mail: arnaud.reynaud@inra.fr

M-H. Nguyen

Toulouse School of Economics, INRA, University of Toulouse Capitole, Toulouse, Tel.: +3361125771, Fax:+33-561128520, E-mail: manh-hung.nguyen@inra.fr

C. Aubert

Gretha, University of Bordeaux \& Toulouse School of Economics, INRA, University of Toulouse Capitole, Toulouse, Fax: +33-561128520, E-mail: cecile.aubert@u-bordeaux.fr
} 


\section{Introduction}

With $89.4 \%$ of its GDP generated in areas at risk, Vietnam is the seventh most exposed country in the world to natural disasters (WorldBank 2005). The average annual cost of natural disasters (including damage to residential housing and public-sector properties, agriculture and infrastructure) is estimated to represent one percent of Vietnamese GDP, with a peak at three percent in 2006 (WorldBank 2010). Flooding is the single most important cause of loss, and it accounts for 49 percent of total economic losses due to natural disasters in Vietnam (WorldBank 2010).

Among the portfolio of policies which can be implemented by public authorities, the development of insurance schemes against natural catastrophes has been advocated for Vietnam by international organizations such as the World Bank or the Asian Development Bank. However, despite the high level of exposure to flood risk, the Vietnamese market for catastrophe insurance remains very small (WorldBank 2010).

A number of studies of flood insurance have been undertaken in developing countries. In Bangladesh, Brouwer and Akter (2010) test the conditions under which rural households favor micro flood insurance to protect themselves against the negative impacts of catastrophic floods. As expected, affordability of insurance premiums plays an important role. Abbas et al. (2015) explore the household willingness to pay (WTP) for flood insurance in a flood-prone area of Pakistan. Although a large proportion of household would be ready to buy flood insurance, their willingness to pay remains limited to around $0.27 \%$ of the mean monthly household income. More recently, Ren and Wang (2016) have estimated the will- 
ingness to buy flood insurance in rural China. They report that about two thirds of the population would be ready to participate in a flood insurance program. They also find that the influencing factors in insurance demand include the recent frequency of floods, income, and past experience with lack of flood insurance. In Vietnam, Brouwer et al. (2014) investigate household willingness and ability to pay for flood micro insurance. They show that there exists a demand for flood insurance, even though a considerable share of the population indicate that they are unable to afford to pay for such insurance.

Several explanations of the low penetration of catastrophe insurance in developing countries have been suggested including problems of adverse selection, lack of awareness and understanding by rural households of the role and operation of flood risk insurance, high administrative costs and high financial exposure due to highly correlated risks.

Here, we explore the demand-side of the flood insurance market by estimating the willingness to pay of Vietnamese households for various flood insurance programs using a choice experiment $(\mathrm{CE})$ approach. Flooding is a low-probability, high-consequence event. Household WTP for flood insurance can be derived from a standard model of insurance demand in which a risk-averse household makes some tradeoffs between the probability of flood occurrence, the magnitude of associated loss and the insurance premium (Kunreuther 1996).

We contribute to the literature on household flood insurance demand in developing countries in several ways. First, we consider flood insurance policies covering either medical expenditures, agricultural losses or home damage. This allows us to check if the WTP for flood insurance differs according to the domain covered. To our best knowledge, only Brouwer and Akter (2010) also consider several types of 
insurance within a choice experiment approach. Second, we examine if non-price demand frictions may help understand the low adoption rate of flood insurance in Vietnam. We focus in particular on two non-price frictions which have been shown to limit insurance demand: the lack of household trust in the institutions providing insurance policies and the household liquidity constraints (Petrolia, Landry, and Coble 2013, Cole et al., 2013). Third, we investigate preference heterogeneity across households for flood insurance policies and we conduct welfare analyses. Fourth, as the recent experience of disasters affects future insurance demand (Browne and Hoyt 2000, Ganderton et al. 2000), we analyze the impact of past experiences of flooding on household WTP.

This paper is organized as follows. Section 2 describes flood risk and the status of flood insurance in Vietnam, and it provides seven hypotheses regarding flood insurance that will be tested in the empirical part. Section 3 presents the design of the choice experiment and its administration. The results of the econometric model are reported in Section 4 and Section 5 concludes the paper.

\section{Flood insurance in Vietnam}

\subsection{Flood risk in Vietnam}

Vietnam is located in the South China Sea and receives heavy rain ranging from 1200 to $3000 \mathrm{~mm}$, nearly $90 \%$ of which occur in summer. In addition to these monsoon rains, 6 to 8 typhoons hit the Vietnamese coasts every year on average. The combination of typhoon and monsoon seasons defines the flooding season which usually starts in July and ends in November. Vietnam ranks seventh in the 
list of countries most exposed to natural disasters, with flooding causing almost half of the total economic losses due to these disasters (WorldBank 2010).

The social cost of flooding is particularly high in Vietnam due to the uneven distribution of the population: $70 \%$ of the population lives in coastal areas, mostly in the Red River Delta in the north and in the Mekong Delta in the south (WorldBank 2010). This coastal population is particularly vulnerable to typhoons and floods since people usually live only a few meters above sea level (Mai, Stive, and VanGelder 2009). Vietnamese people living in mountain areas (30\%) are also vulnerable to flood disasters: Due to the steepness of the terrain, river beds are easily filled by the monsoon rains, frequently leading to flash flooding. This explains why floods have also resulted in a substantial number of deaths and injuries in mountainous zones. The perception of flood risks by the Vietnamese population is high. In a household survey carried out in the Dong Thap Province of Vietnam, $75 \%$ of respondents identified the impact of flooding on the prevalence of disease and ill-health (USSH 2002). The most direct health impacts of flooding are perhaps the deaths and injuries caused by floodwater in or around people's homes (Few, Tran, and Hong 2004). Indirect impacts of flooding on health include diseases related to disruption of normal water/sanitation services and the spreading of contamination by floodwaters (diarrhea and sometimes typhoid, dysentery and cholera) and mosquito-borne diseases related to changes in the breeding conditions for mosquito larvae (malaria or dengue fever). 
2.2 Flood insurance in Vietnam

Coverage for natural catastrophe perils such as flooding is usually included in property insurance policies. In Vietnam (as in most developing countries), subscriptions to property insurance is limited in urban areas, and almost non-existent in rural areas (WorldBank 2010). Catastrophic agricultural insurance is also extremely uncommon. Government disaster relief payments are often the only source of compensation received by farmers following a major flood or storm (WorldBank 2010). Past attempts to introduce multiple-peril crop insurance have been unsuccessful. In 1999, the Vietnamese insurance group Bao Viet stopped offering multiple-peril crop insurance after experiencing high losses. In 2001 the French mutual agricultural insurer Groupama started to sell crop and livestock mortality insurance products. The company has since withdrawn from crop insurance. In July 2012, Vietnam launched a three-year pilot agricultural insurance program. Preliminary results suggest very low adoption rates despite high subsidization. According to the Vietnamese Finance Ministry, only 1 percent of farmers are currently insured against damage to crops. The responsibility for medical expenditures resulting from flood injuries lies with the primary health care system. However, the latter does not have an adequate capacity to deal with storm and flood-related health problems (Van Minh et al. 2014).

\subsection{Hypotheses to be tested}

Based on the existing empirical and theoretical literature on disaster insurance and on the particular characteristics of Vietnam, we formulate a set of seven hypotheses 
which relate flood insurance demand to individual and contractual characteristics.

H1. The demand for flood insurance decreases with the insurance premium.

This hypothesis is an application to insurance of the Law of Demand.

H2. The demand for flood insurance depends upon the maximum coverage.

The maximal insurance coverage (i.e. the maximum amount of money a respondent can be reimbursed in case of a catastrophic flooding event) is typically used by insurance companies in the context of flood risks to avoid moral hazard issues (Hudson et al. 2017). It has been shown that the WTP for flood insurance increases with the maximal insurance coverage (Brouwer and Akter 2010, Botzen and van den Bergh 2012).

H3. The demand for flood insurance is domain-specific.

In Bangladesh, Brouwer and Akter (2010) found a high level of preference heterogeneity across households for flood insurance covering property losses, crop damage and medical expenses. And Reynaud and Nguyen (2016) have shown that the WTP of Vietnamese households for reducing flood risk exposure also depends on whether risk concerns property losses, crop damage or fatality rate.

H4. The demand for flood insurance is impacted by individual risk preferences. 
Individual risk preferences are known to be crucial in explaining decision making under uncertainty (Holt and Laury 2002). Previous research finds that risk aversion increases the likelihood of holding flood insurance or the WTP for flood insurance (Botzen and van den Bergh 2012, Petrolia, Landry, and Coble 2013). This result has however recently been challenged by Cai and Song (2017).

H5. The demand for flood insurance is impacted by past experience of flooding.

There are several reasons why past flood experience matters. First, flood occurrence may be considered a shock that contains new information about flood probabilities. Households may rationally update their beliefs on background risk, with a subsequent impact on the decision to buy insurance (Cameron and Shah 2015). Second, disaster exposure brings more experience, and this, together with the fact that a person has survived and coped with a disaster before, may make her more likely to better cope in the future, which may reduce insurance demand. Third, and to the contrary, having experienced a disaster before may result in more fear and anxiety (Hussain, Weisaeth, and Heir 2011) with a positive effect on flood insurance purchase. Empirical evidence suggests that previous experience affects the demand for disaster insurance (Browne and Hoyt 2000, Ganderton et al. 2000), as well as more specifically for flood insurance (Navrud, Tuan, and Tinh 2012, Petrolia, Landry, and Coble 2013, Seifert et al. 2013, Turner, Said, and Afzal 2014) although the effect of flood events on insurance purchase fades after a few years (Atreya, Ferreira, and Michel-Kerjan 2015). 
H6. The demand for flood insurance is impacted by subjective flood risk perception.

Subjective risk perception is regarded as a crucial element of psychological models describing decision making in relation to threats (Bubeck, Botzen, and Aerts 2012). In the protection motivation theory, which has been used in the context of flood (Grothmann and Reusswig 2006), protection motivation stems from two mediating processes that individuals use in evaluating threats: the threat appraisal and the coping appraisal processes. The threat appraisal process directly relies on subjective risk perception (Grothmann and Reusswig 2006). Empirical evidence regarding the demand for flood insurance and subjective risk perception is however mixed. Botzen and van den Bergh (2012) have elicited the WTP for flood insurance in the Netherlands using a choice experiment. They report a positive statistically significant relationship between individual risk perception and the WTP. A similar result is reported by Seifert et al. (2013) in Germany and the Netherlands. But Hudson et al. (2017) report more recently mixed evidence concerning risk perception and purchase of flood insurance in Germany.

H7. Non-price demand frictions (trust and liquidity constraints) can explain willingness to pay for flood insurance.

A growing empirical literature shows that various types of frictions affect the demand for insurance. For instance, Handel and Kolstad (2015) document the role of information frictions on health insurance choices. Here, we consider two types of non-price frictions particularly relevant for Vietnam: the level of household trust in institutions providing flood insurance policies, and a measure of household 
liquidity constraints (imperfect access to credit markets). First, the lack of trust in the institution providing flood insurance may have a detrimental impact on flood insurance demand (Cole et al. 2013); this is related to the issue of the credibility of insurers discussed in Petrolia, Landry, and Coble (2013). Second, we expect to find that liquidity constraints reduce flood insurance demand as reported in previous empirical studies (Cole et al. 2013). Imperfect access to credit markets is still an important issue in Vietnam where the rural credit market has a dual formal / informal structure; in a study of rural development finance in Vietnam Duong and Izumida (2002) report that as many as 30\% of sampled households are credit-constrained due to limited access to formal lending.

\section{Designing a CE for flood insurance demand in Vietnam}

\subsection{Questionnaire Development}

Our study participants live in the Nghe An Province, in the central part of Vietnam. The topography of the Nghe An province is complex with mountains and hills in the East, and rivers and streams flowing from the North-West to the South-East. The risk of flooding differs significantly depending on location. In the mountains, households face the risk of flash-flooding with the associated risk of landslides. In coastal areas, people are directly affected by typhoons and tropical storms. And people located along rivers or on river delta areas are affected by floods resulting from rivers bursting their banks.

The design of the questionnaire followed a highly iterative process. During the design phase (June 2011 - December 2011), experienced stated choice researchers, natural resource economists and water management experts (both Vietnamese and 
French) reviewed different versions of the questionnaire. Various meetings involving research team members, water experts and local representatives were organized in the Nghe An Province. An initial meeting was held in October 2011 with the representative of the Vietnamese Ministry of Agriculture and Rural Development (MARD) in charge of flood protection in the Nghe An Province. The questionnaire was then significantly modified. A second version was presented in November 2011 to a household representative in the city of Vinh (Cua Lo district), to a farmer's representative in the Cua Lo district and to a politician in the Quy Hop district. These meetings helped check the respondents' understanding of the survey and resulted in several adjustments to the formulation of explanations and questions, and in significant reshaping. The pilot version of the questionnaire was then tested in December 2011 with face-to-face interviews. Six trained and carefully supervised interviewers interviewed 30 randomly selected households. A preliminary econometric model was estimated using the pilot data and some modifications were made to the questionnaire. In particular the number of choice sets was increased from six to eight since it appeared that this did not raise issues of cognitive capacity $\left.\right|^{1}$

The final survey took place from April 4th to June 10th 2012, a period during which no floods and no natural disasters were recorded in the Nghe An Province. To minimize cultural bias, all interviewers came from the Vanxuan University of Technology at Cua Lo (Nghe An Province). Before contacting any household in a village, we met the head of the village People's Committee in order to obtain formal approval for the survey. During this meeting, the head of village's People Committee was shown documents stating that the survey was officially conducted

\footnotetext{
1 The questionnaire includes two CE. The first CE, which aims at assessing the willingness of Vietnamese households to pay for flood risk reduction, has been analyzed in Reynaud and Nguyen (2016). We focus here on the second CE dedicated to flood insurance.
} 
by members of the VanXuan University of Technology and approved by the Department of Science and Technology of Nghe An Province. At the beginning of each household interview, the official approval of our survey was mentioned. Only a small proportion of all the households contacted (less than 10\%) refused to participate. The average duration of the whole interview was 1 hour and 33 minutes. The respondent to the survey was the household's head or his spouse in $94.7 \%$ of the cases.

3.2 Sampling strategy and sample characteristics

Our sampling strategy is as follows. First, 14 districts (out of 17 in the Nghe An Province) were selected based on geographical characteristics (costal area, plain area, mountain area). Then, based on discussions with local representatives of the Vietnamese Ministry of Agriculture and Rural Development (MARD), two "representative" villages/communes were targeted within each district (there are 417 villages/communes in the Nghe An Province). Finally, within each village/commune 16 households were randomly selected from the listing of registered citizens. Our sampling stratification based on geographical location ensures that our data include all relevant types of floods.

Our dataset consists of 448 households from 28 villages/communes from 14 districts. The head of the household is 49.8 years old on average. Average household size is just over 4 and $19 \%$ of households have at least one child less than 3 years old. Average household income in 2011 was 32.5 million VND per year $2^{2}$ The average household income in our sample is lower than the one reported by the

2 The 2011 exchange rate between 1 USD and VND was around 21,000. 
General Statistics Office of Vietnam for the whole Nghe An province in 2010, 40.8 million $\mathrm{VND} \mathrm{S}^{3}$ This difference could be related to our sampling strategy which may have favored rural areas where households have a lower income, or to the reluctance of respondents to reveal in the survey their true income. In $79.2 \%$ of cases, the main occupation of the head of the household is farming (or fishing). Employees represent $5.6 \%$ of our sample and retired households $5.1 \%$. Lastly, $30.6 \%$ of household heads have attended at least high school.

\subsection{Attributes of flood insurance programs}

The attribute choice in the $\mathrm{CE}$ is based on the existing literature on flood insurance and on the seven hypotheses listed above. It is also the result of several meetings held in the Nghe An Province with experts, local representatives in charge of flood management policy and households' and farmers' representatives.

The exploratory research resulted in the selection of five attributes to describe flood insurance programs: (1) Insurance type; (2) Insurance provider; (3) Maximal annual insurance coverage; (4) Annual insurance premium and (5) Monthly payment. In Table 1, we report the list of attributes with their associated levels. A more extended description of each attribute is also provided in the Supplementary Material: "Instruction sheet for the CE on flood insurance".

[Table 1, about here]

Attribute (1) describes the type of flood insurance. It is used to test hypothesis H3 by varying the domain covered by the program: Health insurance covers

\footnotetext{
$3 \longdiv { \text { http://www.gso.gov.vn/ } }$
} 
all medical expenditures due to the occurrence of a catastrophic flood; Agricultural insurance covers crop, livestock and fish losses; House insurance protects respondents' homes and home contents.

Attribute (2) describes the provider of the flood insurance which can be either a state-owned firm, a privately-owned firm or an NGO. It is used to test hypothesis H6. Brouwer and Akter (2010) proposed a similar distinction between insurance providers by considering private insurance companies, central government, local micro credit providers and local user-group cooperatives.

Attribute (3) is the maximal annual insurance coverage. It corresponds to the maximum amount of money a respondent can be reimbursed in the case of a catastrophic flooding event. Varying the maximal insurance coverage allows testing hypothesis H2. Maximum coverage has been used as a program attribute in the context of flood insurance by Botzen and van den Bergh (2012) and Brouwer and Akter (2010).

Attribute (4) describes the annual insurance premium which must be paid by the respondent to have access to the proposed insurance scheme. Risk premiums vary from one type of insurance to another. They are computed as a percentage of the maximal annual insurance coverage. Attribute (4) is used to test hypothesis H1.

Attribute (5) identifies whether or not the respondent has the opportunity to pay the insurance premium on a monthly basis instead of annually. This attribute is introduced in order to capture the impact of household liquidity constraints and imperfect access to the credit market. It is used to test hypothesis H6. 
3.4 Construction of choice sets

To construct the choice sets we implemented a fractional factorial design using the Ngene Software. We then selected a particular subset of complete factorials, so that particular effects of interest could be estimated as efficiently as possible according to the D-optimal criterion. The D-optimal criterion has become the most widely used measure of efficiency because of its insensitivity to the magnitude of the scale of the parameters (Street, Burgess, and Louviere 2005). Priors in the Ngene software have been informed using the econometric results of the pilot version of the questionnaire tested in December 2011.

We constructed 32 choice sets, each consisting of three alternative scenarios (two flood insurance programs and the status quo scenario). To limit cognitive load, the 32 choice sets have been grouped into 4 versions of the CE, each containing 8 choice sets. An example of the choice sets used for the $\mathrm{CE}$ is provided in the Supplementary Material: "Instruction sheet for the CE on flood insurance".

3.5 Additional potential drivers of flood insurance demand

\subsubsection{Trust in insurance provider}

A potential driver of household preferences is the household's confidence in the ability of various institutions to efficiently provide flood insurance (hypothesis $\mathrm{H} 7)$.

We asked each respondent to indicate her level of trust in various insurance providers using the following question: "In many countries, households can use insurance to reduce the impact of flooding on their lives. Flood insurance is usually 
provided by different institutions (state-owned firms, private firms, NGOs, local cooperatives). For each institution, please indicate whether you are confident that this institution could efficiently provide flood insurance. Use a scale from 1 (not at all confident) to 10 (very confident)."

Respondents' answers show more confidence when flood insurance is provided by a state-owned firm: the average trust score is 6.382 in that case compared to 4.769 and 4.477 for private-owned firms and NGOs respectively.

\subsubsection{Risk preferences}

The willingness to pay for insurance likely depends upon risk preferences (hypothesis H4). We measure preferences with lottery tasks based on Eckel and Grossman (2002) (hereafter EG). The EG task presents respondents with a limited set of lotteries, each entailing a 50/50 chance of winning a low prize or a high prize. Respondents are then asked to choose which lottery they prefer. This design is simple enough to be easily understood by subjects outside the usual convenient sample of university students. This is very important in our context since many of our participants have received little education. We extend the EG framework first by increasing the number of lottery choices per task and second, by adding to the $50 / 50$ chance lottery two additional lottery games involving $40 / 60$ and $20 / 80$ chances of winning a low prize or a high prize, see Table A.1 in Appendix A.

The lottery games are incentivized. The average gain obtained by respondents was $36,800 \mathrm{VND}$. Adding the show-up fee of $85,000 \mathrm{VND}$, the average monetary gain is 121,800 VND (2.4\% of respondents' monthly income). Assuming CRRA (constant relative risk aversion) utility, individual risk preferences are estimated

by maximum likelihood following Harrison and Rutström (2008). This provides for 
each household a unique CRRA coefficient, which will be used as an explanatory variable in the CL model. Our estimates yield a CRRA parameter that varies from 2.04 to 3.00 with an average value of 2.57 , and a standard deviation of 0.15 .

\subsubsection{Previous flood experience}

To test hypothesis $\mathrm{H} 5$ on the impact of past experience on insurance adoption, we surveyed respondents' experience with flooding, flood damage and evacuation due to flood threats, see Table 2 .

[Table 2, about here]

In our sample, in the previous 5 years, $40.4 \%$ of households had their house flooded at least once; $20.3 \%$ had been evacuated from their home at least once; and $4.9 \%$ had one member of the household injured due to flooding.

Concerning the economic impact of floods, $76.1 \%$ of households consider that flooding had represented a significant expenditure over the previous 5 years. Respondents were asked to provide an estimate of the average annual cost of flooding for their household in the previous 5 years, distinguishing damage to their house and house contents, damage to agricultural production and damage to health (all medical expenses due to flooding for any member of the household). The cost of flooding is reported in Table $24^{4}$ The average annual cost of flood damage caused to agricultural and fishery production is 3.5 million VND (14.8\% of annual household income on average). The average annual cost of flood damage caused to houses

\footnotetext{
4 The flood costs reported by households correspond to a subjective assessment. It may be that, when reporting their costs, subjects overestimate or underestimate their real flood expenses for strategic reasons or simply because this information is not easily available. Moreover, they do not include non-monetary costs such as those related to anxiety or distress. The flood costs reported here should therefore be treated with caution.
} 
and house contents is slightly lower, at 2.6 million VND (9.3\% of income). Considering only households who report damage strictly due to flooding, the average damage to houses and house contents increases to 3.7 million VND. Damage to health ranks third in terms of cost with only $1.2 \%$ of annual household income. But if we restrict the sample to households in which at least one member has been injured due to flooding, this percentage increases to $23.98 \%$. This indicates high medical expenditures in case of injury or disease related to flooding. Combining agricultural, house and health damage caused by flooding, the average annual cost of damage reaches 6.4 million VND (25.26\% of average annual household income). This is in line with Navrud, Tuan, and Tinh (2012) who found, on a sample of Vietnamese households located in the Quang Nam Province, that the average flood damage represented approximately $20 \%$ of annual income. The high economic impact of flooding on Vietnamese households is corroborated by the fact that $8.9 \%$ of households plan to move to another area where flood risk is lower. Moreover, $32.3 \%$ considered the risk of flooding in choosing their housing location. It should, however, be stressed that the cost reported by households corresponds to their subjective ex-post assessment of flood damage which may differ from the actual cost; stated intentions should also be treated with caution.

\subsubsection{Subjective flood risk perception}

We measure subjective flood risk perception by asking each respondent his beliefs as to the future frequency of floods in the area in which he lives. The exact question used is: "Now, I would like to get your opinion about flood in the future for you and your household. Compared to the last 10 years, do you expect in your area for 
the next 10 years: More floods; Fewer floods; The same number of floods; I don't know if there will be more or fewer floods".

While $18.1 \%$ of respondents expect more frequent floods, $71.0 \%$ of respondents expect fewer floods and $7.2 \%$ believe the frequency will remain the same (only $3.8 \%$ of respondents don't know how to answer). It is surprising that households expect fewer floods in the future. One possible explanation is that they expect to be less often impacted but also expects floods to be more severe, possibly because of climate change (94.1\% of the respondents report that climate has changed in the area where they live, compared with 10 years ago).

\section{Empirical Analysis}

4.1 Individual choices and status quo responses in the $\mathrm{CE}$

As discussed previously, each household had to complete 8 choice sets. In each choice set each respondent chose between three options: two insurance programs and the status quo (No insurance). An insurance program was chosen in $45.68 \%$ of cases whereas respondents selected the status quo option (No insurance) in $54.32 \%$ of cases. In the CE 117 households ( $26.12 \%$ of our sample) chose the status quo in the 8 proposed choice sets. This high percentage of status quo answers is not unusual in this kind of stated preference analysis (Scarpa, Willis, and Acutt 2007). Although rational choice explanations can be provided, the high number of respondents choosing the status quo option may have a variety of psychological reasons, such as misperceived sunk costs, regret avoidance or mistrust. This is the well-known status quo bias in decision-making, first documented by Samuelson and Zeckhauser (1988). In specifying the random utility model, we address this issue by 
including an alternative specific constant (ASC) in order to capture unobservable influences beyond attributes present in the choice sets (Hoyos 2010).

4.2 Modeling of individual choices

We assume that the unobserved utility of a flood insurance program $j$ can be broken down into two components. The first component, which is deterministic, is expressed by the indirect utility function $V$ defined as a function of the attributes of alternatives, individual characteristics, and a set of unknown parameters. The second component, which is stochastic, is a random error term $\epsilon$ which captures unobservable factors that influence utility. Then, the random utility gained by individual $i$ from choosing program $j$ in a particular choice task $k$ may be written:

$$
U_{i j k}=V\left(X_{i j k} \mid \beta\right)+\epsilon_{i j k}=V_{i j k}+\epsilon_{i j k}
$$

where $X_{i j k}$ denotes a vector of explanatory variables describing program $j$ and respondent $i$, and $\beta$ denotes the corresponding vector of coefficients. Respondents are assumed to choose program $j$ if the utility obtained with this program is greater than that of any alternative program $j^{\prime}$. Because the observed outcome of each choice task $k$ is the selection of one out of $J$ programs, the appropriate econometric model is a discrete choice model expressing the probability that program $j$ is chosen over any other program $j^{\prime}$ in choice task $k$.

Assuming a type I extreme value distribution for $\epsilon^{\prime} s$ in Equation (1) leads to the Conditional Logit (CL) model. The CL model is the basic model used in CE studies. It allows us to assess average individual preferences (Train 2009). 
We start with a basic specification in which the indirect utility derived from a flood insurance program is simply a linear function of all the program's attributes and of the ASC, which is equal to 1 when the "No insurance" program is selected and to zero otherwise. Omitting indexes for simplicity, the specification of the indirect utility function becomes:

$$
\begin{aligned}
V= & A S C \cdot(\alpha)+\text { TypeAgri } \cdot(\beta)+\text { TypeHealth } \cdot(\gamma)+\text { MonthlyPayment } \cdot(\zeta) \\
& + \text { ProvState } \cdot(\eta)+\text { ProvNGO } \cdot(\mu)+\text { MaxCoverage } \cdot(\zeta)+P \cdot(\kappa)
\end{aligned}
$$

where TypeAgri and TypeHealth are dummy variables equal to 1 for agricultural and health insurance respectively (reference category is house insurance), MonthlyPayment is a dummy variable equal to one if a monthly payment is possible, ProvState and ProvNGO are dummy variables equal to 1 if the provider of the insurance program is respectively a state-own firm or an NGO (reference category is private-owned firm), MaxCoverage is the maximum level of insurance coverage (in million VND) and $P$ is the insurance premium (in million VND). See Table B.1 in Appendix B for a more extended definition of all variables used in Table 3 .

[Table 3, about here]

Model (1) in Table 3 gives the estimate of the CL model with this basic specification of the indirect utility function. The overall fit of the model measured by MacFadden's $\rho^{2}$ is correct $(0.114)$, and the model predicts $69.55 \%$ of choices correctly. We reject at $1 \%$ the null hypothesis of all coefficients being equal to zero. Most of the coefficients are significant and all the signs are as expected. We also test the independence of the irrelevant alternatives (IIA) property using the 
(Hausman and McFadden 1984) test. In all cases, we find that the IIA cannot be rejected at the $99 \%$ level. Therefore, the CL model is appropriate to our dataset.

The sign and the high significance of the insurance premium coefficient indicate that the effect on utility of choosing a choice set with a higher payment level is negative, as expected (hypothesis H1).

The positive and significant sign of the $A S C$ coefficient indicates strong preferences for the status quo alternative. As mentioned, there can be many reasons for this preference. Among these, it could be that individuals chose the status quo because they view the flood insurance choice as too complex. However only $10.26 \%$ of respondents who repeatedly chose the status quo reported that the choice experiment was not clear enough. To make the distinction between "true zero bids" and "false zero bids", we asked in the debriefing section of the questionnaire the two following questions: "Given my current economic situation, I cannot pay for flood insurance" and "I don't need any flood insurance". Among the 117 households who always chose the status quo option, only 24 answered negatively both questions, and can thus be considered has "false zero bids" (i.e they need flood insurance and they can pay for flood insurance but they chose the status quo in the $\mathrm{CE}$ ). As a robustness check, we re-estimated the model (1) first by excluding the 117 respondents who always selected the status quo option and, second, by removing the 24 households identified previously as "false zeros". Estimates of the CL model are not statistically different from those presented in Table 3 .

The positive and significant sign of TypeHealth indicates that respondents are more likely to select an insurance that covers medical expenses, rather than house damage or agricultural losses. This is in line with USSH (2002) that finds that $75 \%$ of Vietnamese respondents identified an impact of flooding on the prevalence 
of disease and ill-health. The demand for a flood insurance thus depends upon the domain (hypothesis H3).

The probability of an insurance scheme being chosen increases when the insurance scheme is provided at the state level (in comparison with being provided either by an NGO or a private firm). In the following paragraph, we investigate if this result can be related to difference in trust in insurance providers.

The level of coverage has no significant impact which contradicts hypothesis H2. Offering monthly payments does not increase the probability of an insurance scheme being chosen. This provides no evidence of liquidity constraints impacting flood insurance choices, in contradiction with hypothesis H7.

4.3 Accounting for individual heterogeneity

To account for heterogeneity in the sample we estimate the CL model by including various respondent-specific characteristics as interactions with either the ASC or some attributes of the flood insurance programs. The former captures heterogeneity in choosing the status quo vs. the proposed flood insurance programs and the latter captures heterogeneity in the different attributes.

The specification of the indirect utility function becomes:

$$
\begin{aligned}
V_{i}= & \text { ASC } \cdot\left(\alpha_{1}+\alpha_{2} \cdot Z_{i}\right)+\text { TypeAgri } \cdot\left(\beta_{1}+\beta_{2} \cdot Z_{i}\right)+\text { TypeHealth } \cdot\left(\gamma_{1}+\gamma_{2} \cdot Z_{i}\right) \\
& + \text { MonthlyPayment } \cdot\left(\zeta_{1}+\zeta_{2} \cdot Z_{i}\right)+\text { ProvNGO } \cdot\left(\mu_{1}+\mu_{2} \cdot Z_{i}\right) \\
& + \text { ProvState } \cdot\left(\eta_{1}+\eta_{2} \cdot Z_{i}\right)+\text { MaxCoverage } \cdot\left(\zeta_{1}+\zeta_{2} \cdot Z_{i}\right)+P \cdot\left(\kappa_{1}+\kappa_{2} \cdot Z_{i}\right)
\end{aligned}
$$

where $Z_{i}$ is a vector of respondent-specific social, economic and attitudinal characteristics. After extensive testing of the various possible interactions, we select 
the CL models presented in Column (2)-(8) in Table 3 Interaction variables have been selected based on their economic meaning, their significance level and trying to keep the model as parsimonious as possible, see Appendix $B$ for the definition of each variable.

\subsubsection{Past experience with flood}

Past experience with flood is measured by three dummy variables: having one's house flooded at least once (Houseflooded), having been evacuated due to flood at least once (Evacuated) and having one member of the household injured due to flooding (Injured), over the previous 5 years.

In model (2), past flood experience variables have been interacted with the ASC in order to capture individual heterogeneity in choosing the status quo option ("No insurance"). We find a significant and positive sign for the interaction variable between the ASC and Evacuated (being evacuated due to flooding) and Injured (having a member of the household injured). This reflects an unexpectedly higher preference for the status quo option ("No insurance") for evacuated and/or injured households. It may be that being evacuated or injured is not viewed as a traumatic event, or that these events are not frequent enough to be highly valued by respondents. Alternatively, organizing evacuation and taking care of injured people in case of flood could be viewed by respondents as prerogatives of the State, that should not or could not be dealt with using private insurance. The interaction variable between the ASC and Houseflooded is significant and has a negative sign: Flooded households are more likely to select an insurance option in the CE (rather than the "No insurance" option) compared to non-flooded ones. In model (3) past flood experience variables have been interacted with the insurance 
premium $(P)$ to identify heterogeneity in WTP for flood insurance. Being flooded increases the WTP to pay for flood insurance whereas the opposite holds for being evacuated or injured.

Past flood experience thus has a significant impact on flood insurance take up and on WTP (hypothesis H5). The nature of this impact strongly depends however upon the type of flood experience (having one's house flooded vs. being evacuated and being injured).

\subsubsection{Individual risk preferences}

We created a dummy variable (HighCrra) for highly risk-averse households, i.e for households with a CRRA larger than 2.74, which represents a little more than $11.4 \%$ of our household sample. HighCrra has been interacted both with the ASC and the insurance premium variables, see models (4) and (5) in Table 3. We find that highly risk-averse respondents are more likely to select an insurance option in the CE, and have a higher WTP for a flood insurance program. This validates hypothesis $\mathrm{H} 4$ that states that the demand for flood insurance is impacted by individual risk preferences.

\subsubsection{Subjective flood risk perception}

In line with Expected Utility theory, the probability of adopting insurance should be related to respondents' expectations concerning future floods. We created a dummy variable (MoreFlood) if a respondent expects more floods over the next 10 years, which is the case for $18.08 \%$ of our sample. MoreFlood has been interacted both with the ASC and the insurance premium variables, see model (6) and (7) in Table 3. We find that respondents expecting more floods in the future are 
less likely to select an insurance program in the $\mathrm{CE}$, a result which is, a priori, counter-intuitive. One possible explanation is that households who expect more floods may rely on other mitigation and adaption strategies such as relocation in less flood-prone areas. This explanation is related to the fact that $8.93 \%$ of the surveyed households declare that they plan to move to another area where flood risk is lower. If we restrict the sample to households expecting more flood in the future, this percentage increases to $18.52 \%$. Hypothesis H6 ("The demand for flood insurance is impacted by subjective flood risk perception") is thus partially validated.

\subsubsection{Trust in insurance provider}

Each respondent indicated her level of trust in various insurance providers using a scale going from 1 (not at all confident) to 10 (very confident). By selecting answers 9 or 10, we created three dummy variables: HighTrustState for a high level of trust in state-owned firms (27.46\% of the sample), HighTrustNGO for a high level of trust in NGOs (6.47\% of the sample) and HighTrustPriv for a high level of trust in private firms ( $6.92 \%$ of the sample). These dummy variables have been interacted with the attribute describing the insurance provider in the CE, see model (8). The interaction term ProvState $\times$ HighTrustState is not significant: the probability of an insurance scheme being chosen increases with the fact that the insurance scheme is provided at the state level but it is unrelated to the trust of the respondent in the state-owned firm. On the contrary a high trust level in NGOs is associated with a high respondent's utility if the provider is a NGO $($ ProvNGO $\times$ HighTrustNGO is significant and positive). Similarly, a high trust in private firms results in a high utility when the insurance is provided 
by a private firm (ProvPriv $\times$ HighTrustPriv is significant and positive). This stresses the fact that trust and confidence in institutions (NGOs or private firm) play an important role in insurance adoption in Vietnam. This result is in line with Fatti and Patel (2013) who show that household flood risk perceptions in South Africa are highly influenced by historically distrustful relationships with the local institutions. In our context, we conclude that the level of trust in the ability of institutions to provide flood insurance efficiently is a significant determinant of respondents' choice (hypothesis $\mathrm{H} 7$ ).

\subsection{Willingness To Pay (WTP)}

The interpretation of coefficient estimates in the indirect utility functions is not straightforward except as regards significance. It is more convenient to present the results in terms of marginal willingness to pay (WTP) for a change in the attribute considered. For a given attribute, denoted by Att, the marginal WTP is defined as:

$$
W T P_{A t t}=-\frac{\partial V / \partial A t t}{\partial V / \partial C}
$$

which corresponds to minus the marginal rate of substitution between the attribute considered and the cost of the program.

[Table 4 about here]

In Table 4 we report the marginal WTP obtained for the attributes of our CE. WTPs are based on specification (1) of the CL model in Table 3 . The associated confidence intervals are obtained using the parametric bootstrapping technique proposed by Krinsky and Robb (1986) with 5000 replications (similar intervals have been obtained with the Delta method). 
The highest marginal WTP is found for health insurance. It is equal to 1.338 million VND which represents $4.12 \%$ of the average annual household income. The WTP for insurance covering agricultural losses is not significantly different from zero. This may help understand why agricultural flood insurance remains almost nonexistent in Vietnam. We find a significant positive WTP for insurance provided by a state-owned firm (1.406 million VND).

\subsection{Welfare Analysis}

Since the CE method is consistent with utility maximization and demand theory, one can derive compensating surplus measures (CS) for any flood insurance program described by a specific set of attributes.

$$
\text { [Table 5, about here] }
$$

We consider six different flood insurance scenarios based on the type of risk covered and the level of coverage, see Table 5 . For each type of insurance (agricultural, health and house) we define two different insurance schemes. The High scheme corresponds to a high level of coverage and a high risk premium. The Low scheme corresponds to a low level of coverage and a low risk premium. In defining flood insurance programs, we assume that monthly payments are always possible and that the provider is a state-owned firm.

The compensating surplus obtained for the six different insurance scenarios is presented in the last column in Table 5. We define the CS associated with the scenarios as the difference between the welfare measure under the status quo and the six insurance scenarios. In our case the welfare associated with the status quo situation (no flood insurance) is equal to zero. Formally the welfare in the status 
quo should be computed from the coefficient of the ASC but in such a case all the proposed insurance scenarios would have resulted in a reduction in compensating surplus. Following Adamowicz et al. (1998), we assume that the welfare change can be calculated on the basis of attributes alone. This is a reasonable strategy if respondents' preference for the status quo is essentially driven by psychological motives.

Interestingly, the CS are all positive. Implementing flood insurance policies might result in welfare improvements in Vietnam. The CS is the highest for flood insurance covering medical expenses: it is valued at between 2.314 and 2.364 million VND (between $7.1 \%$ and $7.3 \%$ of the respondents' average annual income). CS for flood insurance covering house or agricultural damages represents between $2.1 \%$ and $3.0 \%$ of the respondents' average annual income. For each type of insurance, respondents always prefer the Low scenario, indicating that they are not ready to pay for a high coverage level.

\section{Conclusion and policy implications}

A choice experiment has been employed to estimate how Vietnamese households value flood insurance mechanisms in the Nghe An Vietnamese Province. Using a conditional logit model, we have computed the willingness to pay (WTP) for different flood insurance programs. We have identified the relationships between the WTP and different attributes of insurance schemes (type of risk covered, level of coverage, insurance provider, billing frequency, insurance premium) with a specific focus on heterogeneity in households' preferences. 
We find a strong preference for the status quo option (no insurance), a result which is not unusual in the environmental valuation literature and which may be explained by the well-known status quo bias in decision-making (Samuelson and Zeckhauser 1988). From a policy perspective, the strong preference for the status quo calls for a careful assessment of respondents' motivations for not adopting any of the proposed flood insurance policies. Respondents' preference for the status quo could have rational explanations, related to affordability and need (as mentioned by respondents), but may also be driven by psychological reasons or be protest answers to the CE.

We do, however, document the fact that flood insurance may be an effective option for Vietnamese households. Indeed, $29.24 \%$ of respondents included flood insurance as one of their four preferred policies for managing flood risk. Moreover, in the CE, $73.88 \%$ of the respondents selected at least one program with flood insurance (within eight choice sets they had to complete). Our results call for a careful design of flood insurance policies. In particular, we find that trust in the ability of institutions to efficiently provide flood insurance is a significant determinant of the decision to buy insurance. Since households appear to differ in their trust in various flood insurance providers (state-owned firms, NGOs or privatelyowned firms), a portfolio of providers should be considered when implementing flood insurance on a large scale. Households would then select their preferred provider and one might expect an increase in the flood insurance adoption rate.

Our results also reveal very different levels of willingness to pay for flood insurance policies depending on the type of risk covered. First, the WTP for flood insurance covering agricultural losses is non-significant. This helps understand why past attempts to implement agricultural flood insurance have failed in Vietnam. 
It may also help understand why only farmers receiving a 100\% subsidy have subscribed to the flood insurance proposed in the pilot program launched by the Vietnamese government in June 2012. Second, willingness to pay is highest for insuring the health consequences of floods, at 1.338 million VND (4.12\% of average annual household income). This is surprising given the fact that Vietnamese households report relatively low average medical expenses due to floods (less than $1.2 \%$ of their annual income). One explanation could be a higher level of household risk aversion for health risks, possibly since self-protection is more difficult to achieve for such risks compared with agricultural production or house risks. Our results thus suggest scope for extending health insurance policies in order to cover medical expenses resulting from floods.

Lastly, in order to increase the likelihood of flood insurance adoption, one may consider bundling different flood insurance policies. Bundling can be useful when individuals have heterogeneous valuations and also allows to benefit from complementarities. Public authorities may for instance propose a flood insurance jointly covering damage to health and damage to homes and home contents.

Acknowledgements The authors would like to thank Mr. Nhung Nguyen from the Vietnamese Ministry of Agriculture and Rural Development for his patience when explaining the organization of flood protection in Vietnam and in the Nghe An Province. We also thank Thanh Duy Nguyen for his very efficient assistance during the field work. We are also grateful to Richard Carson and all participants at the Environmental Economics Lunch Seminar at UC San Diego for their valuable comments. This research is funded by Vietnam National Foundation for Science and Technology Development (NAFOSTED) under grant number 502.012016.18 (project ECO-EROSION-VIET). 


\section{References}

Abbas, A., T. S. Amjath-Babu, H. Kächele, And K. Müller (2015): "Non-structural flood risk mitigation under developing country conditions: an analysis on the determinants of willingness to pay for flood insurance in rural Pakistan," Natural Hazards, 75(3), 2119-2135.

Adamowicz, W., P. Boxall, M. Williams, And J. Louviere (1998): "Stated Preference Approaches for Measuring Passive Use Values: Choice Experiments and Contingent Valuation," American Journal of Agricultural Economics, 80(1), 64-75.

Atreya, A., S. Ferreira, and E. Michel-Kerjan (2015): "What drives households to buy flood insurance? New evidence from Georgia," Ecological Economics, 117, 153 - 161.

Botzen, W., And J. van den Bergh (2012): "Monetary Valuation of Insurance against Climate Change Risk," International Economic Review, 53(3), 1005-1026.

Brouwer, R., ANd S. Akter (2010): "Informing micro insurance contract design to mitigate climate change catastrophe risks using choice experiments," Environmental Hazards, 9(1), $74-88$.

Brouwer, R., B. D. Tinh, T. H. Tuan, K. Magnussen, and S. Navrud (2014): "Modeling demand for catastrophic flood risk insurance in coastal zones in Vietnam using choice experiments," Environment and Development Economics, 19, 228-249.

Browne, M. J., And R. E. Hoyt (2000): "The Demand for Flood Insurance: Empirical Evidence," Journal of Risk and Uncertainty, 20(3), 291-306.

Bubeck, P., W. J. W. Botzen, and J. C. J. H. Aerts (2012): "A Review of Risk Perceptions and Other Factors that Influence Flood Mitigation Behavior," Risk Analysis, 32(9), $1481-1495$

CAI, J., And C. Song (2017): "Do disaster experience and knowledge affect insurance take-up decisions?," Journal of Development Economics, 124, 83 - 94.

Cameron, L., And M. Shah (2015): "Risk-Taking Behavior in the Wake of Natural Disasters," Journal of Human Resources, 50(2), 484-515.

Cole, S., X. Giné, J. Tobacman, P. Topalova, R. Townsend, and J. Vickery (2013): "Barriers to Household Risk Management: Evidence from India," American Economic Journal: Applied Economics, 5(1), 104-135. 
Duong, P. B., And Y. Izumida (2002): "Rural Development Finance in Vietnam: A Microeconometric Analysis of Household Surveys," World Development, 30(2), 319 - 335.

Eckel, C., And P. Grossman (2002): "Sex Differences and Statistical Stereotyping in Attitudes Toward Financial Risk," Evolution and Human Behavior, 23(4), 281-295.

FAtti, C. E., And Z. PAtel (2013): "Perceptions and responses to urban flood risk: Implications for climate governance in the South," Applied Geography, 36, 13-22.

FEw, R., P. Tran, AND B. Hong (2004): Living with the floods: health risks and coping strategies of the urban poor in Vietnam. Research report for the British Academy (Committee for South East Asian Studies).

Ganderton, P. T., D. S. Brookshire, M. McKee, S. Stewart, and H. Thurston (2000): "Buying Insurance for Disaster-Type Risks: Experimental Evidence," Journal of Risk and Uncertainty, 20(3), 271-289.

Grothmann, T., And F. Reusswig (2006): "People at Risk of Flooding: Why Some Residents Take Precautionary Action While Others Do Not," Natural Hazards, 38, 101-120, $10.1007 / \mathrm{s} 11069-005-8604-6$.

Handel, B. R., And J. T. Kolstad (2015): "Health Insurance for "Humans": Information Frictions, Plan Choice, and Consumer Welfare," American Economic Review, 105(8), 24492500.

Harrison, G., And E. Rutström (2008): Risk aversion in the laboratoryRisk aversion in Experiments. J.C. Cox and G.W. Harrison (Ed.), Research in Experimental Economics volume 12, pp. $41-196$.

Hausman, J., And D. McFadden (1984): "Specification Tests for the Multinomial Logit Model," Econometrica, 52(5), 1219-1240.

Holt, C. A., And S. K. Laury (2002): "Risk Aversion and Incentive Effects," American Economic Review, 92(5), 1644-1655.

Hoyos, D. (2010): "The state of the art of environmental valuation with discrete choice experiments," Ecological Economics, 69(8), 1595 - 1603.

Hudson, P., W. W. Botzen, J. Czajkowski, and H. Kreibich (2017): "Moral Hazard in Natural Disaster Insurance Markets: Empirical Evidence from Germany and the United States," Land Economics, 93(2), 179-208. 
Hussain, A., L. Weisaeth, and T. Heir (2011): "Psychiatric disorders and functional impairment among disaster victims after exposure to a natural disaster: A population based study," Journal of Affective Disorders, 128(1-2), 135-141.

Krinsky, I., And A. L. Robb (1986): "On Approximating the Statistical Properties of Elasticities," The Review of Economics and Statistics, 68(4), 715-719.

Kunreuther, H. (1996): "Mitigating Disaster Losses through Insurance," Journal of Risk and Uncertainty, 12(2/3), 171-187.

Mai, C. V., M. J. Stive, and P. H. VanGelder (2009): "Coastal Protection Strategies for the Red River Delta," Journal of Coastal Research, pp. 105-116.

Navrud, S., T. H. Tuan, And B. D. Tinh (2012): "Estimating the welfare loss to households from natural disasters in developing countries: a contingent valuation study of flooding in Vietnam," Global Health Action, 5, 17609.

Petrolia, D. R., C. E. Landry, and K. H. Coble (2013): "Risk Preferences, Risk Perceptions, and Flood Insurance," Land Economics, 89(2), 227-245.

Ren, J., AND H. H. WANG (2016): "Rural Homeowners' Willingness to Buy Flood Insurance," Emerging Markets Finance and Trade, 52(5), 1156-1166.

Reynaud, A., And M.-H. Nguyen (2016): "Valuing Flood Risk Reductions," Environmental Modeling \& Assessment, 21(5), 603-617.

Samuelson, W., and R. Zeckhauser (1988): "Status quo bias in decision making," Journal of Risk and Uncertainty, 1, 7-59.

Scarpa, R., K. G. Willis, and M. Acutt (2007): "Valuing externalities from water supply: Status quo, choice complexity and individual random effects in panel kernel logit analysis of choice experiments," Journal of Environmental Planning and Management, 50(4), 449-466. Seifert, I., W. J. W. Botzen, H. Kreibich, and J. C. J. H. Aerts (2013): "Influence of flood risk characteristics on flood insurance demand: a comparison between Germany and the Netherlands," Natural Hazards and Earth System Sciences, 13(7), 1691-1705.

Street, D. J., L. Burgess, And J. J. Louviere (2005): "Quick and easy choice sets: Constructing optimal and nearly optimal stated choice experiments," International Journal of Research in Marketing, 22(4), $459-470$.

Train, K. E. (2009): Discrete Choice Methods with Simulation. Cambridge University Press. 
Turner, G., F. Said, And U. Afzal (2014): "Microinsurance Demand After a Rare Flood Event: Evidence From a Field Experiment in Pakistan," The Geneva Papers on Risk and Insurance - Issues and Practice, 39(2), 201-223.

USSH (2002): Perception of people on environmental sanitation in Mekong River Delta: Fact and Solutions. Unpublished report. Department of Geography, University of Social Sciences and Humanities, Hochiminh City.

Van Minh, H., T. T. Anh, J. Rocklöv, K. B. Giang, L. Q. Trang, K.-G. Sahlen, M. Nilsson, And L. Weinehall (2014): "Primary healthcare system capacities for responding to storm and flood-related health problems: a case study from a rural district in central Vietnam," Global Health Action, 7(1), 4-14.

WorldBank (2005): Natural Disaster Hotspots: A Global Risk Analysis. Disaster Risk Management Series No. 5, Hazard Management Unit, The World Bank.

(2010): Weathering the Storm: Options for Disaster Risk Financing in Vietnam. The World Bank. 
Table 1 Attributes and levels used in the CE

\begin{tabular}{lll}
\hline Attribute description & Attribute levels & Status no \\
\hline Insurance type & Health, Agricultural, House & None \\
Insurance provider & State-owned firm, Private-owned firm, NGO & None \\
& & None \\
Maximal annual insurance coverage & 5,10 (million VND) & \\
- for health insurance & $5,10,15$ (million VND) & \\
- for agricultural insurance & $5,10,15,20,40$ (million VND) & \\
& & None \\
Annual insurance premium* & $2 \%, 4 \%, 6 \%$ & \\
- for health insurance & $2 \%, 4 \%, 6 \%$ & \\
- for agricultural insurance & $2 \%, 4 \%, 6 \%, 8 \%, 10 \%$ & \\
& & \\
Monthly payment & Yes, No & None \\
\hline * In the choice sets, the insurance premium is presented as a monetary value (VND). For each type \\
$\begin{array}{l}\text { of insurance, the risk premiums correspond to the percentage provided in this Table multiplied by the } \\
\text { maximal annual insurance coverage. }\end{array}$
\end{tabular}


Table 2 Household flood history and cost of flooding in the last 5 years

\begin{tabular}{|c|c|c|}
\hline Variable & Mean & Std. Dev. \\
\hline \multicolumn{3}{|l|}{ Household flood history } \\
\hline House flooded at least once in the last 5 years & 0.404 & 0.491 \\
\hline Respondent evacuated at least once in the last 5 years & 0.203 & 0.403 \\
\hline One household member injured at least once in the last 5 years & 0.049 & 0.216 \\
\hline Respondent has considered risk of flooding to choosing housing location & 0.323 & 0.468 \\
\hline Respondent plan to move to another location due to flood risk & 0.089 & 0.285 \\
\hline \multicolumn{3}{|l|}{ Cost of flooding* } \\
\hline Flooding has represented a significant cost in the last 5 years & 0.761 & 0.427 \\
\hline House cost (million VND) & 2.636 & 6.543 \\
\hline Agricultural cost (million VND) & 3.536 & 7.720 \\
\hline Health cost (million VND) & 0.249 & 1.320 \\
\hline Total cost (million VND) & 6.421 & 11.137 \\
\hline House cost (\% of income) & 9.287 & 22.198 \\
\hline Agricultural cost (\% of income) & 14.798 & 27.642 \\
\hline Health cost ( $\%$ of income) & 1.170 & 7.370 \\
\hline Total cost (\% of income) & 25.256 & 37.022 \\
\hline
\end{tabular}

* Due to missing answers, flood costs have been computed on a sub-sample of 407 households. 
Table 3 CL models

\begin{tabular}{|c|c|c|c|c|c|c|c|c|}
\hline & $(1)$ & $(2)$ & $(3)$ & $(4)$ & $(5)$ & (6) & $(7)$ & $(8)$ \\
\hline$A S C$ & $\begin{array}{c}1.346^{* * *} \\
(13.31)\end{array}$ & $\begin{array}{c}1.358^{* * *} \\
(12.62)\end{array}$ & $\begin{array}{c}1.338^{* * *} \\
(13.20)\end{array}$ & $\begin{array}{c}1.415^{* * *} \\
(13.80)\end{array}$ & $\begin{array}{c}1.342^{* * *} \\
(13.26)\end{array}$ & $\begin{array}{c}1.275^{* * *} \\
(12.31)\end{array}$ & $\begin{array}{c}1.345^{* * *} \\
(13.30)\end{array}$ & $\begin{array}{c}1.381^{* * *} \\
(13.46)\end{array}$ \\
\hline TypeAgri & $\begin{array}{c}-0.0194 \\
(-0.26)\end{array}$ & $\begin{array}{c}-0.00952 \\
(-0.13)\end{array}$ & $\begin{array}{c}-0.0149 \\
(-0.20)\end{array}$ & $\begin{array}{c}-0.0176 \\
(-0.23)\end{array}$ & $\begin{array}{c}-0.0181 \\
(-0.24)\end{array}$ & $\begin{array}{c}-0.0278 \\
(-0.37)\end{array}$ & $\begin{array}{c}-0.0197 \\
(-0.26)\end{array}$ & $\begin{array}{c}-0.0153 \\
(-0.20)\end{array}$ \\
\hline TypeHealth & $\begin{array}{c}0.670^{* * *} \\
(8.19)\end{array}$ & $\begin{array}{c}0.678^{* * * *} \\
(8.27)\end{array}$ & $\begin{array}{c}0.665^{* * *} \\
(8.12)\end{array}$ & $\begin{array}{c}0.671^{* * * *} \\
(8.20)\end{array}$ & $\begin{array}{c}0.669^{* * *} \\
(8.17)\end{array}$ & $\begin{array}{c}0.667^{* * * *} \\
(8.14)\end{array}$ & $\begin{array}{c}0.671^{* * * *} \\
(8.19)\end{array}$ & $\begin{array}{c}0.677^{* * * *} \\
(8.25)\end{array}$ \\
\hline ProvState & $\begin{array}{c}0.705^{* * * *} \\
(10.10)\end{array}$ & $\begin{array}{c}0.710^{* * * *} \\
(10.16)\end{array}$ & $\begin{array}{c}0.712^{* * * *} \\
(10.19)\end{array}$ & $\begin{array}{c}0.708^{* * *} \\
(10.14)\end{array}$ & $\begin{array}{c}0.707^{* * * *} \\
(10.13)\end{array}$ & $\begin{array}{c}0.701^{* * * *} \\
(10.04)\end{array}$ & $\begin{array}{c}0.704^{* * * *} \\
(10.09)\end{array}$ & $\begin{array}{c}0.721^{* * * *} \\
(9.23)\end{array}$ \\
\hline ProvNGO & $\begin{array}{c}-0.0109 \\
(-0.14)\end{array}$ & $\begin{array}{c}-0.00861 \\
(-0.11)\end{array}$ & $\begin{array}{c}-0.00785 \\
(-0.10)\end{array}$ & $\begin{array}{c}-0.00912 \\
(-0.12)\end{array}$ & $\begin{array}{c}-0.00955 \\
(-0.12)\end{array}$ & $\begin{array}{c}-0.0145 \\
(-0.19)\end{array}$ & $\begin{array}{c}-0.0111 \\
(-0.14)\end{array}$ & $\begin{array}{c}-0.0382 \\
(-0.47)\end{array}$ \\
\hline MonthlyPayment & $\begin{array}{c}-0.0658 \\
(-1.10)\end{array}$ & $\begin{array}{c}-0.0669 \\
(-1.12)\end{array}$ & $\begin{array}{c}-0.0623 \\
(-1.04)\end{array}$ & $\begin{array}{c}-0.0660 \\
(-1.10)\end{array}$ & $\begin{array}{c}-0.0671 \\
(-1.12)\end{array}$ & $\begin{array}{c}-0.0651 \\
(-1.09)\end{array}$ & $\begin{array}{c}-0.0659 \\
(-1.10)\end{array}$ & $\begin{array}{c}-0.0692 \\
(-1.15)\end{array}$ \\
\hline MaxCoverage & $\begin{array}{c}-0.00495 \\
(-0.93)\end{array}$ & $\begin{array}{c}-0.00477 \\
(-0.90)\end{array}$ & $\begin{array}{c}-0.00516 \\
(-0.97)\end{array}$ & $\begin{array}{c}-0.00488 \\
(-0.92)\end{array}$ & $\begin{array}{c}-0.00498 \\
(-0.94)\end{array}$ & $\begin{array}{c}-0.00525 \\
(-0.99)\end{array}$ & $\begin{array}{c}-0.00495 \\
(-0.93)\end{array}$ & $\begin{array}{c}-0.00486 \\
(-0.91)\end{array}$ \\
\hline$P$ & $\begin{array}{c}-0.501 * * * \\
(-4.79)\end{array}$ & $\begin{array}{c}-0.502^{* * *} \\
(-4.80)\end{array}$ & $\begin{array}{c}-0.538 * * * \\
(-4.71)\end{array}$ & $\begin{array}{c}-0.503^{* * *} \\
(-4.81)\end{array}$ & $\begin{array}{c}-0.560 * * * \\
(-5.21)\end{array}$ & $\begin{array}{c}-0.497^{* * *} \\
(-4.75)\end{array}$ & $\begin{array}{c}-0.492^{* * *} \\
(-4.58)\end{array}$ & $\begin{array}{c}-0.506^{* * *} \\
(-4.83)\end{array}$ \\
\hline \multicolumn{9}{|l|}{ Past experience with floods } \\
\hline$\overline{A S C \times \text { Houseflooded }}$ & & $\begin{array}{c}-0.465 * * * \\
(-4.43)\end{array}$ & & & & & & \\
\hline$A S C \times$ Evacuated & & $\begin{array}{c}0.736^{* * *} \\
(5.62)\end{array}$ & & & & & & \\
\hline$A S C \times$ Injured & & $\begin{array}{c}0.852^{* * * *} \\
(3.93)\end{array}$ & & & & & & \\
\hline$P \times$ Houseflooded & & & $\begin{array}{c}0.395^{* * *} \\
(3.27)\end{array}$ & & & & & \\
\hline$P \times$ Evacuated & & & $\begin{array}{c}-0.562^{* * *} \\
(-3.50)\end{array}$ & & & & & \\
\hline$P \times$ Injured & & & $\begin{array}{c}-0.757^{* *} \\
(-2.48)\end{array}$ & & & & & \\
\hline \multicolumn{9}{|l|}{ Risk preferences } \\
\hline$\overline{A S C \times H i g h C r} r a$ & & & & $\begin{array}{c}-0.578^{* * *} \\
(-4.33)\end{array}$ & & & & \\
\hline$P \times H i g h C r r a$ & & & & & $\begin{array}{c}0.424^{* * *} \\
(2.86)\end{array}$ & & & \\
\hline \multicolumn{9}{|l|}{ Subjective flood risk perception } \\
\hline$\overline{A S C \times \text { MoreFlood }}$ & & & & & & $\begin{array}{c}0.351^{* * *} \\
(3.09)\end{array}$ & & \\
\hline$P \times$ MoreFlood & & & & & & & $\begin{array}{c}-0.0478 \\
(-0.35)\end{array}$ & \\
\hline \multicolumn{9}{|l|}{ Trust in insurance providers } \\
\hline$\overline{\text { ProvState } \times \text { HighTrustState }}$ & & & & & & & & $\begin{array}{c}0.0704 \\
(0.63)\end{array}$ \\
\hline ProvNGO × HighTrustNGO & & & & & & & & $\begin{array}{c}0.845^{* * *} \\
(3.91)\end{array}$ \\
\hline ProvPriv $\times$ HighTrustPriv & & & & & & & & $\begin{array}{c}0.482^{* *} \\
(2.25)\end{array}$ \\
\hline $\mathrm{N}$ & 3584 & 3584 & 3584 & 3584 & 3584 & 3584 & 3584 & 3584 \\
\hline Log-likelihood & -5361.9 & -5334.1 & -5350.3 & -5352.6 & -5358.1 & -5357.1 & -5361.9 & -5352.8 \\
\hline MacFadden's $\rho^{2}$ & 0.114 & 0.118 & 0.016 & 0.116 & 0.115 & 0.115 & 0.114 & 0.116 \\
\hline
\end{tabular}

$t$ statistics in parentheses

${ }^{*} p<0.10,{ }^{* *} p<0.05,{ }^{* * *} p<0.01$ 
Table 4 Marginal WTP (in million VND) for flood insurance attributes

\begin{tabular}{lcc}
\hline Attribute & Est. & Confidence interval $(95 \%)$ \\
\hline TypeAgri & -0.038 & $(-0.408 ; 0.242)$ \\
TypeHealth & 1.338 & $(0.870 ; 2.364)$ \\
ProvState & 1.406 & $(0.937 ; 2.434))$ \\
ProvNGO & -0.021 & $(-0.334 ; 0.305)$ \\
MonthlyPayment & -0.131 & $(-0.385 ; 0.111)$ \\
MaxCoverage & -0.010 & $(-0.044 ; 0.008)$ \\
\hline Note: Marginal WTP is based on model (1) in Table 3 \\
Confidence intervals obtained with 5000 replications using \\
the method proposed by Krinsky and Robb (1986).
\end{tabular}

Table 5 Welfare analysis for flood insurance scenarios

\begin{tabular}{llcccccc}
\hline \multirow{2}{*}{$\begin{array}{l}\text { Scenario } \\
\text { name }\end{array}$} & Type & Provider & $\begin{array}{c}\text { Max. cover. } \\
\text { (million VND) }\end{array}$ & $\begin{array}{c}\text { Risk premium } \\
(\text { million VND) }\end{array}$ & $\begin{array}{c}\text { Monthly } \\
\text { payment }\end{array}$ & $\begin{array}{c}\text { Compensating } \\
\text { surplus } \\
\text { (million VND) }\end{array}$ & $\begin{array}{c}\text { Confidence } \\
\text { interval } \\
(95 \%)\end{array}$ \\
\hline Health $^{H}$ & Health & SOF & 10 & 0.2 & yes & 2.314 & $(1.234 ; 3.395)$ \\
Health $^{L}$ & Health & SOF & 5 & 0.1 & yes & 2.464 & $(1.320 ; 3.608)$ \\
House $^{H}$ & House & SOF & 20 & 0.4 & yes & 0.678 & $(0.173 ; 1.182)$ \\
House $^{L}$ & House & SOF & 10 & 0.2 & yes & 0.976 & $(0.435 ; 1.518)$ \\
Agri $^{H}$ & Agri. & SOF & 15 & 0.3 & yes & 0.788 & $(0.231 ; 1.346)$ \\
Agri $^{L}$ & Agri. & SOF & 10 & 0.2 & yes & 0.938 & $(0.379 ; 1.497)$ \\
\hline
\end{tabular}

Note: Compensating surplus is based on model (1) in Table 3

$\mathrm{SOF}$ for state-owned firm. 
A Definition of Lottery Task

Table A.1 Definition of Lottery Tasks

\begin{tabular}{llcccc}
\hline $\begin{array}{l}\text { Task } \\
\text { Number }\end{array}$ & $\begin{array}{l}\text { Lottery } \\
\text { Number }\end{array}$ & $\begin{array}{c}\text { Payoff } \\
\text { (Hight) }\end{array}$ & $\begin{array}{c}\text { Prob. } \\
\text { (Hight) }\end{array}$ & $\begin{array}{c}\text { Payoff } \\
\text { (Low) }\end{array}$ & $\begin{array}{c}\text { Prob. } \\
\text { (Low) }\end{array}$ \\
\hline 1 & 1 & 94200 & 0.5 & 600 & 0.5 \\
1 & 2 & 93600 & 0.5 & 3000 & 0.5 \\
1 & 3 & 90000 & 0.5 & 6000 & 0.5 \\
1 & 4 & 85200 & 0.5 & 9000 & 0.5 \\
1 & 5 & 81000 & 0.5 & 10800 & 0.5 \\
1 & 6 & 73200 & 0.5 & 13200 & 0.5 \\
1 & 7 & 66000 & 0.5 & 15000 & 0.5 \\
1 & 8 & 63000 & 0.5 & 15600 & 0.5 \\
1 & 9 & 59400 & 0.5 & 16200 & 0.5 \\
\hline 2 & 1 & 87500 & 0.6 & 10000 & 0.4 \\
2 & 2 & 82500 & 0.6 & 15000 & 0.4 \\
2 & 3 & 77500 & 0.6 & 20000 & 0.4 \\
2 & 4 & 74000 & 0.6 & 23000 & 0.4 \\
2 & 5 & 71000 & 0.6 & 25000 & 0.4 \\
2 & 6 & 67500 & 0.6 & 27500 & 0.4 \\
2 & 7 & 64000 & 0.6 & 30000 & 0.4 \\
2 & 8 & 61000 & 0.6 & 32000 & 0.4 \\
2 & 9 & 58000 & 0.6 & 34000 & 0.4 \\
\hline 3 & 1 & 60000 & 0.8 & 7000 & 0.2 \\
3 & 2 & 59000 & 0.8 & 10000 & 0.2 \\
3 & 3 & 58000 & 0.8 & 13000 & 0.2 \\
3 & 4 & 57000 & 0.8 & 15000 & 0.2 \\
3 & 5 & 56000 & 0.8 & 16500 & 0.2 \\
3 & 6 & 55000 & 0.8 & 18000 & 0.2 \\
3 & 7 & 54000 & 0.8 & 19500 & 0.2 \\
3 & 8 & 53000 & 0.8 & 20500 & 0.2 \\
3 & 9 & 52000 & 0.8 & 21500 & 0.2 \\
\hline All payoffs are expressed in Vietnamese Dongs (VND)
\end{tabular}

All payoffs are expressed in Vietnamese Dongs (VND). 


\section{B Definition of variables}

Table B.1 Name and definition of variables used in the empirical application

\begin{tabular}{|c|c|}
\hline Variable & Definition \\
\hline \multicolumn{2}{|l|}{ Attributes of the CE } \\
\hline$\overline{A S C}$ & Dummy variable equal to 1 if the "No insurance" program is selected. \\
\hline TypeAgri & Dummy variable equal to 1 if insurance covers agricultural losses. \\
\hline TypeHealth & Dummy variable equal to 1 if insurance covers medical expenses. \\
\hline TypeHouse & Dummy variable equal to 1 if insurance covers house damage. \\
\hline ProvState & Dummy variable equal to 1 if insurance provided by a state-owned firm. \\
\hline ProvNGO & Dummy variable equal to 1 if insurance provided by a NGO. \\
\hline ProvPriv & Dummy variable equal to 1 if insurance provided by a private firm. \\
\hline MaxCoverage & Maximum cover in case of flood damage (in million VND). \\
\hline MonthlyPayment & Dummy variable equal to 1 if monthly payment is possible. \\
\hline$P$ & Annual insurance premium (in million VND). \\
\hline \multicolumn{2}{|c|}{ Other explanatory variables } \\
\hline Houseflooded & $\begin{array}{l}\text { Dummy variable equal to } 1 \text { if respondent reports that house has been flooded at least once } \\
\text { in the previous } 5 \text { years }(0 / 1)\end{array}$ \\
\hline Evacuated & $\begin{array}{l}\text { Dummy variable equal to } 1 \text { if respondent has been evacuated or advised to evacuate from } \\
\text { his/her house because of the threat of flooding }(0 / 1)\end{array}$ \\
\hline Injured & $\begin{array}{l}\text { Dummy variable equal to } 1 \text { if a member of the household has been injured by a flood event } \\
\text { in the last } 5 \text { years }(0 / 1)\end{array}$ \\
\hline HighTrustState & $\begin{array}{l}\text { Dummy variable equal to } 1 \text { if respondent has a high level of trust in a state-owned firm to } \\
\text { efficiently provide a flood insurance. Trust is measured on a scale going from } 1 \text { to } 10 \text {, with } 1 \\
\text { for no trust at all and } 10 \text { for total trust. High trust corresponds to modalities } 8 \text { and 9.) }\end{array}$ \\
\hline HighTrustPriv & $\begin{array}{l}\text { Dummy variable equal to } 1 \text { if respondent has a high level of trust in a private firm to efficiently } \\
\text { provide a flood insurance. Trust is measured on a scale going from } 1 \text { to } 10 \text {, with } 1 \text { for no } \\
\text { trust at all and } 10 \text { for total trust. High trust corresponds to modalities } 8 \text { and } 9 \text {. }\end{array}$ \\
\hline HighTrustNGO & $\begin{array}{l}\text { Dummy variable equal to } 1 \text { if respondent has a high level of trust in a NGO to efficiently } \\
\text { provide a flood insurance. Trust is measured on a scale going from } 1 \text { to } 10 \text {, with } 1 \text { for no } \\
\text { trust at all and } 10 \text { for total trust. High trust corresponds to modalities } 8 \text { and } 9 \text {. }\end{array}$ \\
\hline MoreFlood & Dummy variable if a respondent expects more floods in the next 10 years. \\
\hline HighCrra & $\begin{array}{l}\text { Dummy variable if the respondent is highly risk-averse. A high risk-averse respondent is } \\
\text { defined by a constant relative risk aversion coefficient greater than } 2.74 \text {. }\end{array}$ \\
\hline
\end{tabular}

